\title{
Neuronal Cell Proliferation and Ocular Enlargement in Black Moor Goldfish
}

PAMELA A. RAYMOND, PETER F. HITCHCOCK, AND MICHAEL F. PALOPOLI Departments of Anatomy and Cell Biology (P.A.R., P.F.H., M.F.P.) and Ophthalmology (P.F.H.), The University of Michigan Medical School, Ann Arbor, Michigan 48109-0616

\begin{abstract}
The mechanisms that control cell proliferation in the developing nervous system are not well understood. In larval and adult goldfish addition of new retinal neurons continues as the eye grows, but the factors that modulate the rate of cell proliferation are unknown. The eyes of Black Moors grow excessively during postembryonic life, probably as a direct result of abnormally elevated intraocular pressure. Ocular growth must be partly autonomous in Black Moors because in some individuals the two eyes are very different in size. To determine whether cell proliferation and neuronal cell number in the retina were correlated with size of the eye, we counted dividing neuronal progenitor cells (rod precursors) and mature retinal neurons (ganglion cells) in the retinas of ocularly asymmetric fish. Rod precursors, which are scattered across the retina in the outer nuclear layer, were labeled with ${ }^{3} \mathrm{H}$-thymidine and counted on histological sections processed for autoradiography. Ganglion cells were counted in retinal whole mounts. We found that the total population of dividing rod precursors and the total number of ganglion cells were systematically greater in the large eye compared to the small eye of individual fish. We conclude that control of the rate of neuronal proliferation in the teleost retina is intrinsic to the eye and is probably regulated by the same factors that control ocular growth.
\end{abstract}

Key words: neuronal hyperplasia, mitogenic factors, thymidine autoradiography, ganglion cells

Neuronal proliferation in the retina has been well described, and recently some insights have been gained into its control. For example, in the mammalian retina, ganglion cells are initially overproduced, and once proliferation ends, the correct number is established by culling those that send their axons to inappropriate locations within the brain (e.g., O'Leary et al., '86). Other evidence suggests that specific intercellular interactions among different cell types play a role in regulating cell production. For example, in fish (Negishi et al., '82, '87) and frogs (Reh and Tully, '86; Reh, '87) selective neurotoxic destruction of dopaminergic amacrine cells or other neuronal types results in a transient up-regulation in the production of new ones in the peripheral germinal zone, whereas the rate of production of unaffected neurons remains unchanged. However, it is not at all clear how this specific modulation of cell proliferation is brought about. In general, the factors that regulate the rate of neuronal cell proliferation during embryogenesis and during later stages of growth are largely unknown (Stewart et al., '86). In other tissues, growth reg. ulation has been studied more extensively. In the epider- mis, for example, cell production is regulated through negative feedback mediated by tissue-specific inhibitory hormones (Duell et al., '75) and by mechanical factors such as wounding and stretching (Bertsch et al., '76).

Here we describe the relationship between ocular and retinal size and neurogenesis in a mutant goldfish, the Black Moor. In this fish ocular growth is excessive and extremely variable (Fig. 1). Retinal area is correlated with ocular size. The proximal cause of this abnormality is thought to lie within the eye (Raymond et al., '84; Easter and Hitchcock, '86). To determine whether an increased rate of cell proliferation contributes to the excessive retinal growth, Black Moor fish with asymmetric eyes were injected with ${ }^{3} \mathrm{H}$-thymidine to label dividing cells. Labeled cells were counted and the numbers compared between the two eyes. Three fish were examined, and in each the larger

Accepted April 19, 1988.

Dr. Pamela A. Raymond published previously as Pamela R. Johns. 
of the two eyes had more dividing cells. To determine whether increased proliferation actually resulted in the production of more neurons (neuronal hyperplasia), ganglion cells were counted in four additional Black Moors with ocular asymmetry. In each of these animals the average planimetric density of ganglion cells (No. per $\mathrm{mm}^{2}$ ) was lower in the larger retina than in the smaller one, but the product of cell density and retinal area showed that the larger retina consistently contained more ganglion cells. These data suggest the following: 1) in the Black Moor excessive retinal growth is accompanied by neuronal hyperplasia, and 2) in these animals the rate of retinal neurogenesis is regulated by factors that determine ocular growth.

\section{MATERIALS AND METHODS}

Black Moor goldfish (Carassius auratus) obtained from Grassyfork Fisheries (Martinsville, IN) were maintained at $18-20^{\circ} \mathrm{C}$ in aerated artificial pond water (Allee et al., '40) in 10-gallon aquaria.

\section{Thymidine autoradiography}

Three fish with asymmetric eyes were injected intraperitoneally with a single dose of ${ }^{3} \mathrm{H}$-thymidine, $10 \mu \mathrm{Ci} / \mathrm{g}$ (specific activity: $95 \mathrm{Ci} / \mathrm{mmol}$, New England Nuclear). Their body weights were 16,18 , and $23 \mathrm{~g}$. Twenty-four hours later the animals were anesthetized by immersion in $0.2 \%$ aqueous tricaine methanesulfonate, decapitated, and their eyes were removed. The intact eyes were fixed overnight in $3 \%$ glutaraldehyde, $3 \%$ paraformaldehyde, $0.1 \%$ picric acid in $0.1 \mathrm{M}$ phosphate buffer, $\mathrm{pH} 7.2$, at approximately $4^{\circ} \mathrm{C}$. Eyes were fixed intact in order to minimize distortion of the globe.

The following day, the cornea was opened, the lens was removed, and its diameter was measured with a caliper. The eyecup was then bisected along the dorsoventral meridian. Half-eyes were transferred to fresh, cold fixative, agitated gently for 1 hour, rinsed in $0.1 \mathrm{M}$ phosphate buffer (pH 7.2), dehydrated, and embedded in methacrylate (Sorval Embedding Medium, Dupont). Polymerization of the resin took place at approximately $4^{\circ} \mathrm{C}$.

Serial sections were cut at $3 \mu \mathrm{m}$ on 0.5 -inch-wide glass knives with a JB-4 microtome (Sorvall-Dupont). Every 2025 th section was mounted on an acid-cleaned slide and dried on a hot plate at about $80^{\circ} \mathrm{C}$. The plane of sectioning was parallel to the dorsoventral meridian.

For autoradiography, slides were processed in Kodak NTB-2 emulsion according to standard procedures (Rogers, '79). Slides were exposed for $1.5-17$ weeks at about $4^{\circ} \mathrm{C}$. All slides used to count labeled cells in the retinas of a single individual were exposed for the same length of time and were processed together. Sections were poststained with Lee's combination of methylene blue and basic fuchsin (Polysciences Data Sheet \#123). Slides were then air dried, cleared in xylenes, and coverslipped with D.P.X. (BDH Chemicals, Poole, England).

Labeled cells were counted at $625 \times$ magnification by means of darkfield optics. Twenty-five to 56 sections were examined from each eye. All labeled cells in the outer nuclear layer (ONL) were counted in each section. The criterion for a cell to be labelled was five or more silver grains over the nucleus. These dividing cells are rod precursors, which produce new rod photoreceptors during retinal growth (Johns, '82; Raymond, '85). All counts were made by one investiqator (M.F.P.). Repeat counts on the same sections after a 2 -week interval differed by less than $10 \%$.
No correction was made for split nuclei since we were interested only in comparing labeled cells between the two eyes of a given fish, and so the absolute magnitude of the counts was not important.

\section{Morphometric techniques}

We were interested in estimating the total number of labeled cells in the retina, and for this we needed to know retinal area and planimetric density of labeled cells. We could not determine the retinal area directly from the histological sections since we did not have a complete serial set. We therefore examined other Black Moor eyes prepared with a method originally developed for assessing the geometry of eyes from common goldfish (Easter et al., '77). We determined the relationship between retinal area, lens diameter, and meridional retinal length. The retinal area of the eyes prepared for autoradiography could then be calculated from lens diameter (measured when the lens was removed from the eye before embedding) and meridional retinal length (measured from tracings of the histological sections; see below).

Briefly, the procedure for determining the geometry of Black Moor eyes (Easter and Hitchcock, '86) was to freeze intact, freshly enucleated eyes and mount them on the freezing stage of a horizontal, sliding microtome, with either the dorsoventral or nasotemporal axis of the eye parallel to the surface of the stage. The eye was then sliced, the sections were discarded, and photographs of the block face were taken every $200-400 \mu \mathrm{m}$. From the collection of 35 $\mathrm{mm}$ photographic slides, the one that included the plane passing through the center of the eye was identified; in this section, the diameter of the eye is maximal. The photographic slides were mounted on the stage of a projecting microscope (Micro Promar, Leitz), and the image was projected onto a sheet of paper at a magnification of $9-15 \times$. The outlines of retina and lens were traced, and the follow-

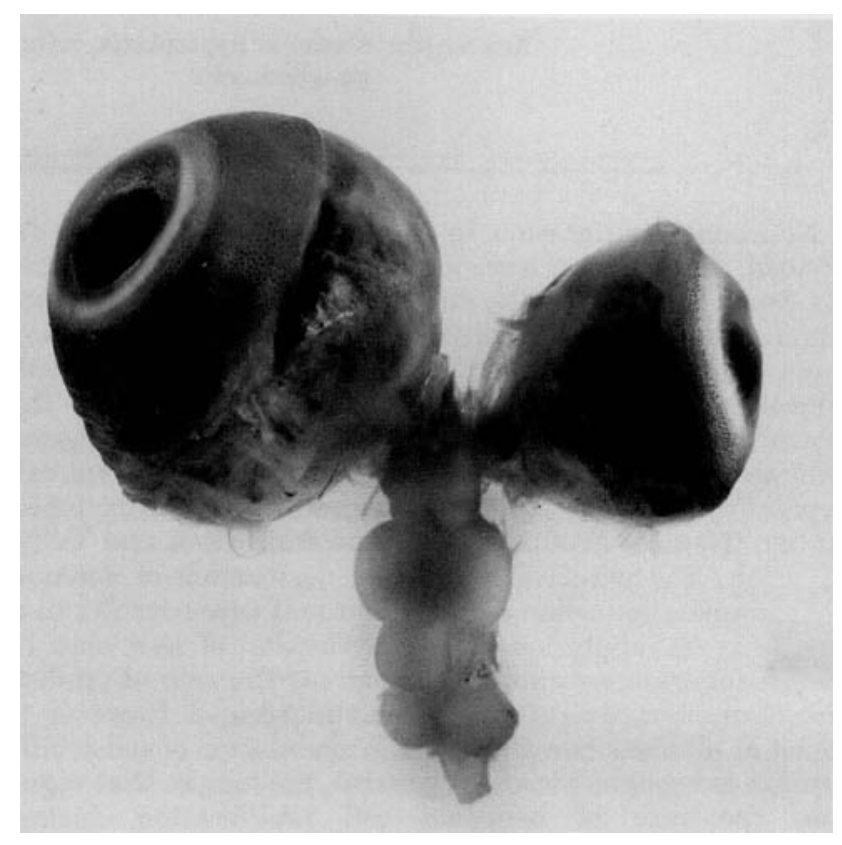

Fig. 1. Photograph of the dissected brain and eyes of a Black Moor goldfish with asymmetric eyes. Magnification: approximately $3 \times$. 
ing dimensions were measured on the tracings: 1) lens diameter $\left.\left(d_{1}\right), 2\right)$ meridional retinal length $\left(l_{r}\right)$, defined as the linear distance along the retina from one margin to the other at midlevel in the retina, and 3 ) the angle subtended by the retina $(\rho)$, measured with respect to the center of the globe. From these data, a linear regression was calculated to estimate $\rho$ as a function of $l_{r}$ and $d_{l}$. (See Results for further explanation.)

Similar tracings were then made from the histological preparations, at a magnification of $22 \times$, by using the projecting microscope. For each eye the lens diameter had been measured after fixation as described above. The meridional (i.e., maximal) retinal length was estimated by measuring the linear extent of the retina on tracings of each histological section and selecting the largest value. Measurements were corrected for histological shrinkage, estimated to be

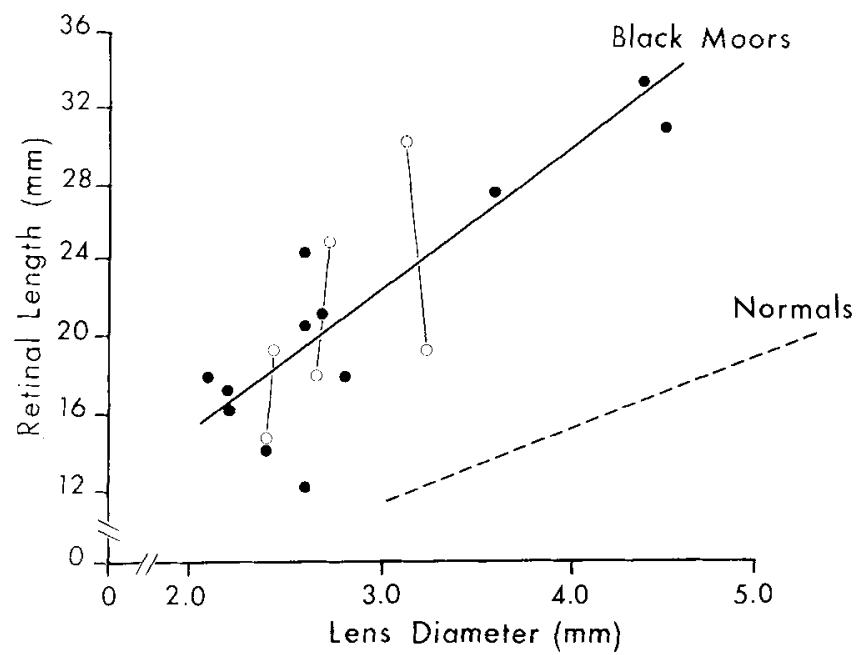

Fig. 2. Retinal length is proportional to lens diameter. The data points each represent one retina. The filled circles are measurements from photographs of frozen, sliced Black Moor eyes (See Materals and Methods), and the open circles are measurements from histological sections of six eyes from three fish; values representing the two retinas from each individual are connected by thin lines. The thick, solid line through the data points is the least squares linear regression $\left(l_{r}=7.5 \times d_{1}, r^{2}=0.80\right)$. The dashed line is the regression for common goldfish $\left(l_{r}=3.8 \times d_{1}, r^{2}=0.96\right.$; from Easter et al., '77).

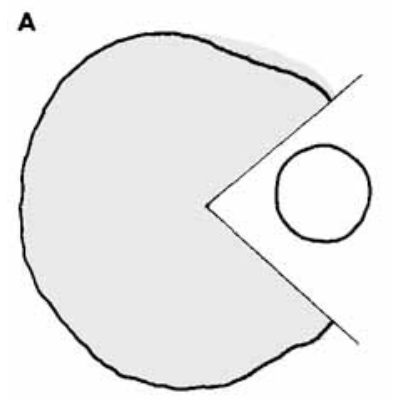

B

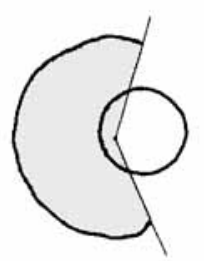

c

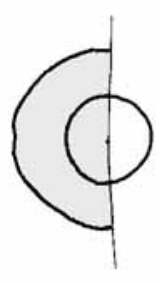

$15 \%$. The angle subtended was then calculated from the regression equation determined above.

From the photographs of frozen, sliced eyes we determined that the retina could be approximated as a portion of a sphere (see Fig. 3). The radius of the sphere ( $r$ ) was calculated by using the proportionality:

$$
\frac{2 \pi \mathbf{r}}{l_{r}}=\frac{360}{\rho}
$$

and therefore:

$$
\mathrm{r}=57.3 \frac{\mathrm{l}_{\mathrm{r}}}{\rho}
$$

The surface area of the retina (A) was then calculated:

$$
\mathrm{A}=2 \pi \mathrm{r}^{2} \int_{0}^{\rho / 2} \sin \rho \mathrm{d} \rho=2 \pi \mathrm{r}^{2}[1-\cos (\rho / 2)]
$$

Density (D) of labeled nuclei in the ONL was calculated by assuming each section to be a rectangle of length $=1_{r}$, the retinal length, and width $=3 \mu \mathrm{m}$, the section thickness. Therefore $\mathrm{D}=(\mathrm{ONL}$ cell count $) /\left(\mathrm{l}_{\mathrm{r}} \times 3 \mu \mathrm{m}\right)$. For each eye the total number of labelled cells in the ONL was determined by averaging the density of labeled cells (D) across all sections and calculating the product of $\bar{D} \times A$.

\section{Ganglion cell counts}

Retinal whole mounts were prepared from both eyes of four ocularly asymmetric fish. The fish were dark adapted for 1-2 hours and then deeply anesthesized as before. Both eyes were removed; retinas were isolated from the eyecups and whole-mounted on gelatinized slides, receptor-side down, as described by Hitchcock and Easter ('86). Whole mounts were then fixed for 30 minutes in $2 \%$ glutaraldehyde. Great care was taken to remove the entire retina, and this was assured by including the annular blood vessel, which lies at the retinal margin. The above procedure resulted in no obvious distortions of the whole-mounted retinas, and as shown previously (Hitchcock and Easter, '86), results in less than $20 \%$ linear shrinkage. Slides were stained with $0.5 \%$ Toluidine Blue, dehydrated in alcohols, cleared in xylenes, and coverslipped with Histoclad (Clay Adams).

Ganglion cell somata were distinguished from macrophages, glial cells, and endothelial cells by the relative differences in soma size, shape, and staining characteristics (see Hitchcock and Easter, '86). Macrophages and glia could not be separately identified, but both were very small, had densely staining Nissl substance, contained little cytoplasm, were irregularly shaped, and did not contain an easily identifiable nucleus. Endothelial cell nuclei were pale staining and tubular in shape. Ganglion cells were relatively large, generally round in shape, contained abundant cytoplasm, and possessed an easily identified nucleus and nucleolus. No attempt was made to distinguish ganglion cells from displaced amacrine cells, which are very rare in goldfish (Hitchcock and Easter, '86).

In normal goldfish there are no major regional variations in ganglion cell density, e.g., fovea, area centralis, or horizontal streak (Johns and Easter, '77; Kock and Reuter, '78;

Fig. 3. Comparison of ocular geometries in Black Moor and common goldfish. These are drawings made from photographs of frozen, sliced eyes (see Materials and Methods). The outer line traces the retina and the circular profile is the lens. The stippled region was defined by selecting the circle which best fit the contours of the retina. Line segments were drawn from the center of this circle to the margins of the retina, and the angle subtended by the retina $(\rho$ in equations 1,2 , and 3; see Materials and common goldfish. Scale bar is $1.0 \mathrm{~mm}$. 

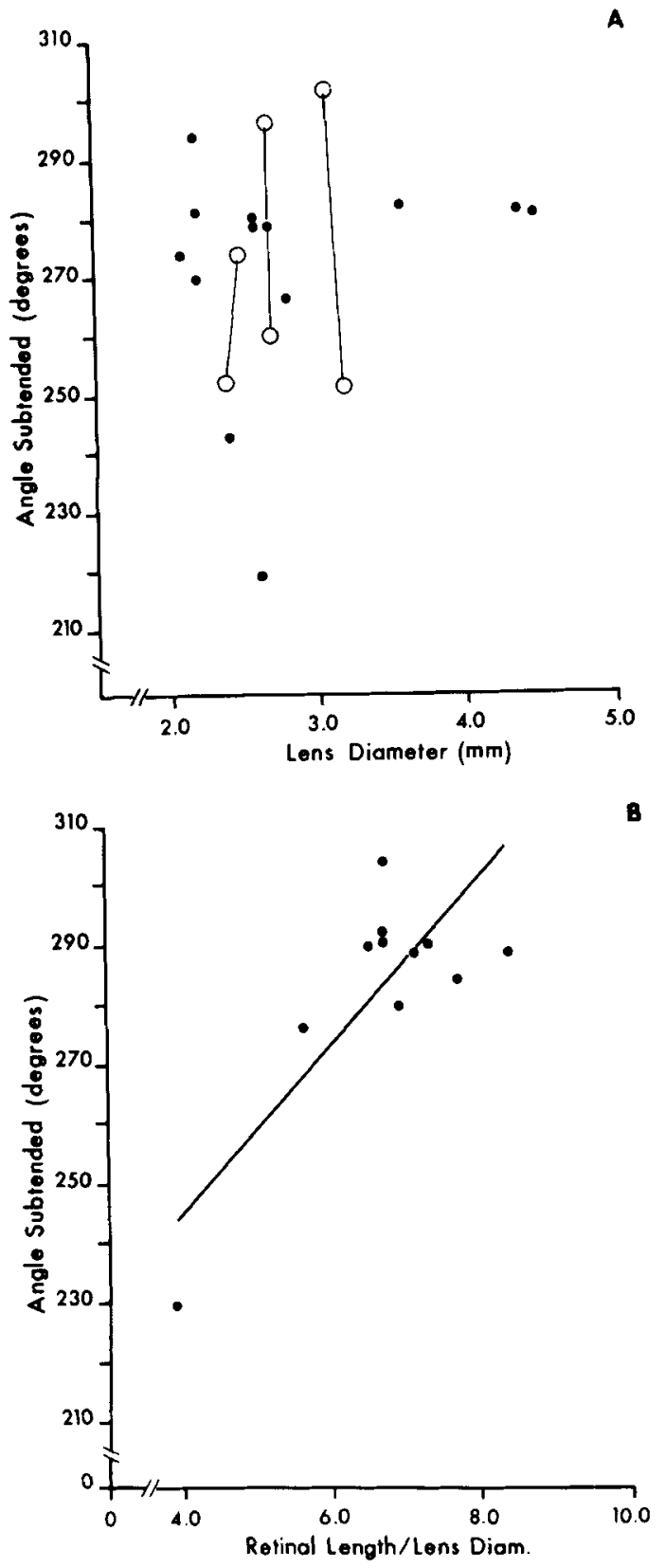

Fig. 4. Relationship between angle subtended by retina, retinal length and lens diameter. Panel A: Angular subtense is not correlated with lens diameter. Panel B: Angular subtense is proportional to the ratio:retinal length/lens diameter. Least squares linear regression:

$$
\rho=13.6 \frac{\mathrm{l}_{\mathrm{r}}}{\mathrm{d}_{\mathrm{l}}}+168.6, \mathrm{r}^{2}=0.66
$$

The values of $\rho$ corresponding to the six retinas processed for autoradiography (open circles) were calculated from the above regression; filled circles represent actual measurements from frozen, sliced eyes.

however, see Mednick and Springer, '88), and none was observed in the retinas of the Black Moors (Hitchcock, unpublished observations). Therefore, a straightforward sampling method was used to estimate ganglion cell numbers. Camera lucida drawings of each retina were divided into four concentric regions of equal area and then into

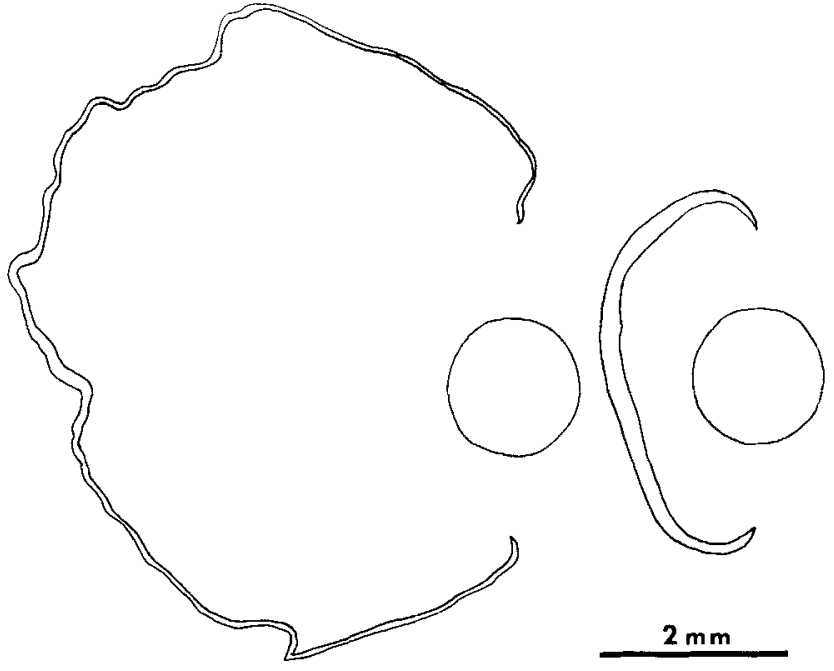

Fig. 5. Thinning of the retina in Black Moor goldfish. These are camera Iucida tracings of retinal sections from a Black Moor (left) and a common goldfish (right), with comparable lens diameters. The two circles represent the lenses. The retinal tracings are bounded by the inner limiting membrane and Bruch's membrane. Note that the Black Moor retina collapsed during histological processing, as did all these retinas we examined.

quadrants centered on the optic disc (see Fig. 7). By using the camera lucida drawings as guides, cells were counted in five nonadjacent fields $(1,250 \times$ magnification; 0.0176 $\mathrm{mm}^{2}$ in area) within each of the 16 regions. From these 80 sampling points an average cell density was computed and multiplied by the area of the retina to give an estimate of the total number of ganglion cells. Areas were computed by tracing the retinal outlines on the digitizing pad of a ZeissMOP. The number of cells counted in each retina averaged $1.5 \%$ of the estimated total. All counts were made by one investigator (P.F.H.)

\section{Statistics}

Statistical analyses were made by means of the MannWhitney U test (Krauth, '83).

\section{RESULTS Ocular geometry}

The eyes and retinas of Black Moor goldfish are grossly enlarged (Easter and Hitchcock, '86), but the lenses are relatively unaffected. The diameter of the lens in a Black Moor's eye is approximately the same as in a normal goldfish of similar body size (Raymond, unpublished observations), and the lenses from the two eyes of a given fish are the same size even when the sizes of the globes are quite different (Easter and Hitchcock, '86, and Fig. 3). Figure 2 shows the relationship between meridional retinal length and lens diameter in Black Moors and common goldfish. For eyes with comparable lens diameters, the size of the retina is systematically greater in Black Moors (Figs. 2, 3).

The posterior chamber of the Black Moor eye is approximately spherical (Fig. 3) with the exception of the area immediately surrounding the optic disc, which often bulges outward (Easter and Hitchcock, '86). Panels A, B, and C in Figure 3 are drawings from photographs of frozen, sliced eyes from two Black Moors and a normal goldfish, respectively. Note the large variations in retinal length and angular subtense, despite the similarities in lens sizes. 

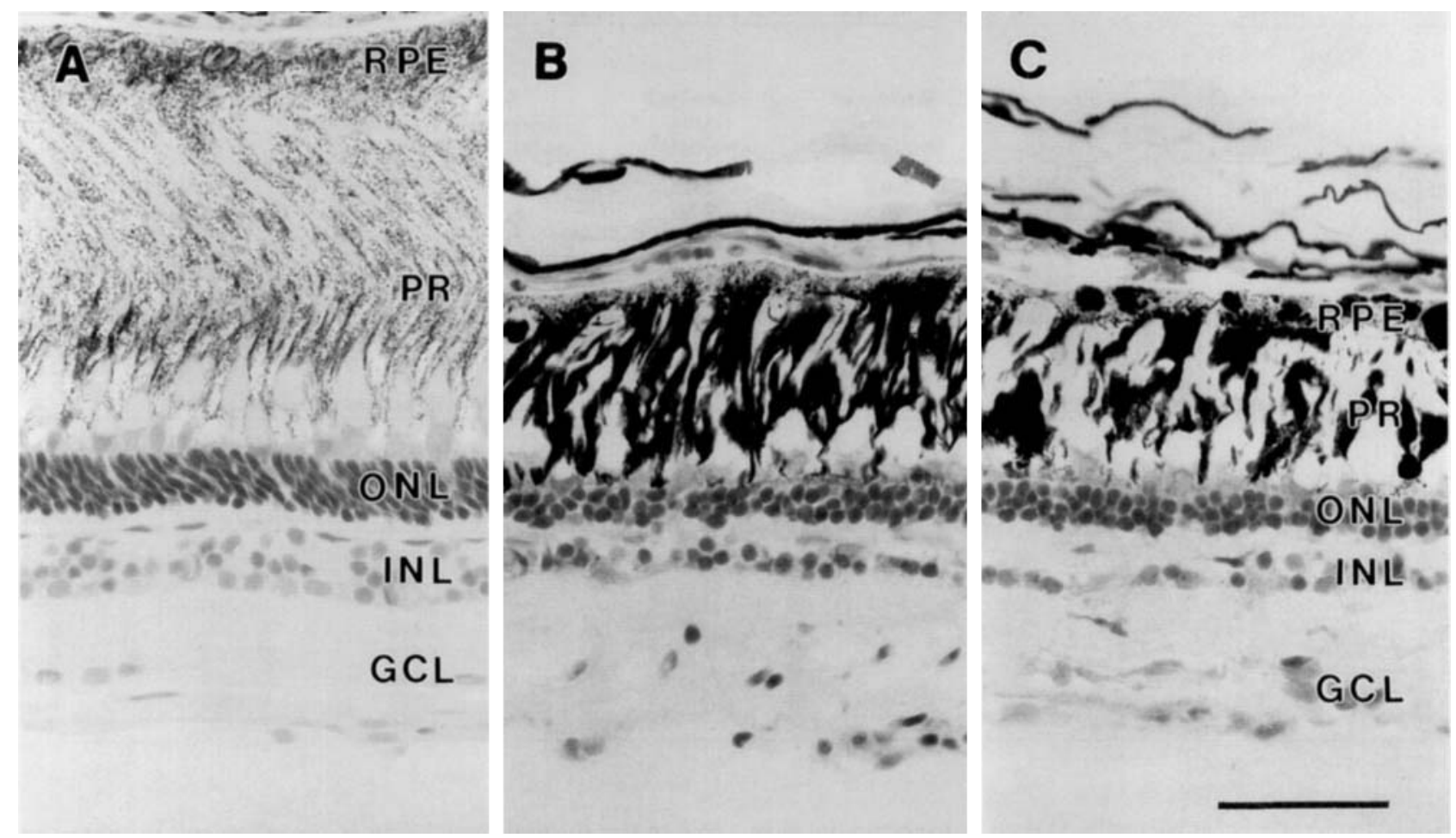

Fig. 6. Comparison of retinal histology in Black Moor and common goldfish. A: Common goldfish. B: Smaller eye of ocular asymmetric Black Moor (MA3 on Table 1). C: Larger eye of same individual. Retinal pigmented

epithelium, RPE: photoreceptor processes, PR; outer nuclear layer, ONL; inner nuclear layer, INL; ganglion cell layer, GCL. Scale bar equals $50 \mu \mathrm{m}$ and applies to all panels.

The diameter of the globe in Black Moors is highly variable and not proportional to body size (Easter and Hitchcock, '86), as it is in common goldfish (Johns and Easter, '77). The solid angle ( $($ ) subtended by the retina in common goldfish is constant $\left(185^{\circ}\right)$ regardless of eye size (Easter et al., '77), but in Black Moor eyes this angle was variable and in all cases greater than $185^{\circ}$ (Fig. 4A). It is clear from Figure 4A that the angular subtense of the retina could not be predicted from the lens diameter. However, when angular subtense of the retina was plotted as a function of the ratio retinal length $\left(\mathrm{l}_{\mathrm{r}}\right) /$ lens diameter $\left(\mathrm{d}_{1}\right)$, a linear relationship emerged (Fig. 4B), which was described by the regression equation:

$$
\rho(\text { degrees })=13.6 \frac{l_{\mathrm{r}}}{\mathrm{d}_{1}}+168.6
$$

This equation was used to estimate the angular subtense $(\rho)$ of the six retinas used in the counts of labeled cells (see Table I), and from $\rho$ and $l_{r}$, the surface area (A) of each retina was determined using equations I and II (see Materials and Methods).

\section{Retinal histology}

The retinas of Black Moors were thinner than those of common goldfish (Fig. 5). Figure 6 compares histological sections of retinas from a common goldfish (panel A) and a Black Moor (panels B and C, left and right eyes, respectively). The two fish were comparable in body length and had similar lens diameters. The photomicrographs in Fig-

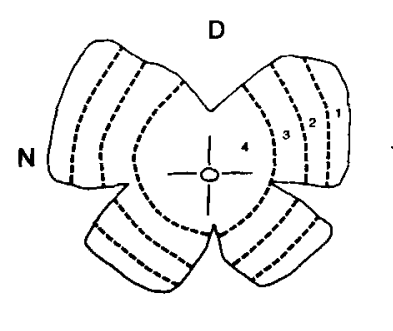

$330 \mathrm{~L}$

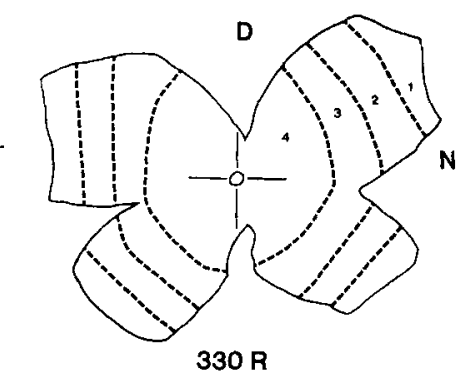

$330 \mathrm{R}$
Fig. 7. Camera lucida drawings of two whole-mounted retinas from an ocularly asymmetric individual used for estimating the number of ganglion cells (see Table 2). The dashed lines divide the retinas into four concentric regions (numbered 1-4), which were further divided into quadrants centered on the optic disc (solid lines), to give a total of 16 separate retinal regions of approximately equal area that were sampled at five separate points (80 separate points per retina). D, dorsal; $N$, nasal; $T$, temporal. Scale bar equals $2.0 \mathrm{~mm}$.

ure 6 are all from central retina, a region just dorsal to the optic disc. Rod nuclei in the ONL were stacked about four rows thick in the common goldfish but only about two rows thick in the Black Moor. The inner nuclear layer was also somewhat thinner, and the melanin in the pigmented epithelium was denser in the mutant. The subretinal space (the region between the layer of pigmented epithelial cells and the ONL) was markedly shrunken in the Black Moor. In the common goldfish, there is a retinal tapetum lucidum in this region (Wheeler, '78), which contributes to the dispersion of melanin and the widening of this layer. The 
TABLE 1. Summary of Labeled Cells in the Outer Nuclear Layer in Black Moor Goldfish With Retinas of Different Sizes

\begin{tabular}{|c|c|c|c|c|c|c|c|c|}
\hline Eye & $\begin{array}{c}\text { Standard } \\
\text { body length } \\
(\mathrm{cm})\end{array}$ & $\begin{array}{c}\text { Lens } \\
\text { diameter } \\
(\mathrm{mm})\end{array}$ & $\begin{array}{c}\text { Meridional } \\
\text { retinal } \\
\text { length }(\mathrm{mm})\end{array}$ & $\begin{array}{c}\text { Estimated } \\
\text { retinal } \\
\text { area }\left(\mathrm{mm}^{2}\right)\end{array}$ & $\begin{array}{c}\% \\
\text { difference } \\
\text { retinal area }\end{array}$ & $\begin{array}{l}\text { Average } \\
\text { labeled } \\
\text { cell } \\
\text { density } \\
\left(\mathrm{mm}^{2}\right)\end{array}$ & $\begin{array}{c}\text { Total } \\
\text { labeled } \\
\text { cells }\end{array}$ & $\begin{array}{c}\% \\
\text { difference } \\
\text { total } \\
\text { cells }\end{array}$ \\
\hline MA1R & 8.0 & 3.3 & 16.5 & 148 & - & 229 & 33,800 & - \\
\hline MA1L & - & 3.1 & 25.8 & 309 & 52 & 402 & 124,300 & 73 \\
\hline MA2L & 6.0 & 2.7 & 15.3 & 123 & - & 127 & 15,600 & - \\
\hline MA2R & - & 2.7 & 21.2 & 214 & 42 & 123 & 26,300 & 41 \\
\hline MA3L & 5.8 & 2.4 & 12.3 & 81 & - & 167 & 13,500 & - \\
\hline MA3R & - & 2.5 & 16.3 & 134 & 40 & 165 & 22,100 & 39 \\
\hline
\end{tabular}

TABLE 2. Summary of Estimated Numbers of Ganglion Cells in Black Moor Goldfish With Retinas of Different Sizes

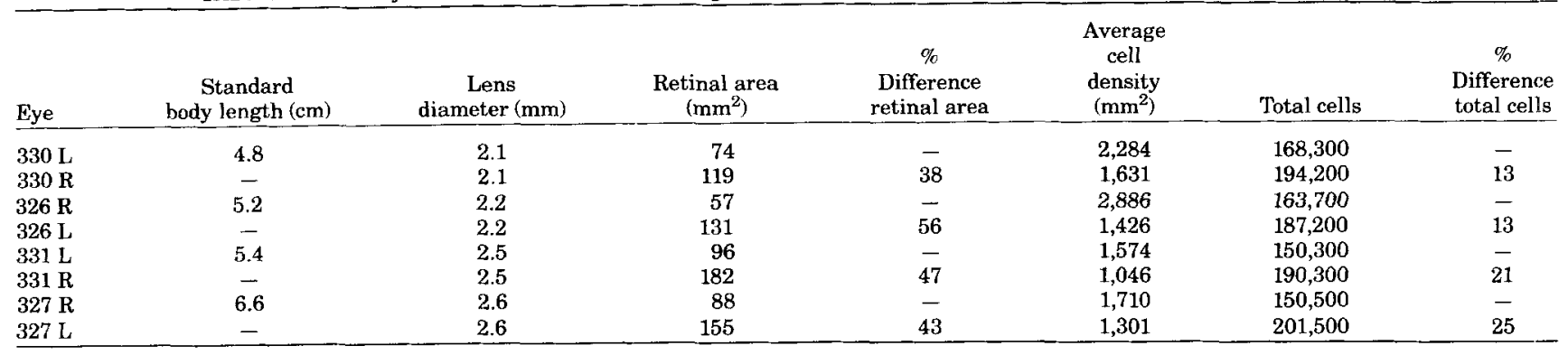

Black Moor retinas apparently lacked a tapetum in this region (Fig. 6B,C).

The seven fish selected for cell counts had asymmetric eyes similar to the fish illustrated in Figure 1. The percent difference in retinal area between the larger and smaller eye of a given individual ranged from 38 to $56 \%$. For three of the fish (MA1, MA2, MA3, see Table 1) the volume of each eye was measured by fluid displacement after immersion in buffer, and the small eye was about half the volume of the large eye.

\section{Effect on cell proliferation}

Table 1 summarizes the data from the thymidine autoradiographic study. The estimated total numbers of labeled cells in the ONL ranged from 13,500 to 124,300 . There was a positive correlation between the size of the retina and the estimated total number of labeled cells $\left(r^{2}=0.85\right)$. The planimetric densities of the labeled ONL cells (No. cells per $\mathrm{mm}^{2}$ retinal surface area) were about the same between the two eyes for the two smallest fish (MA2, MA3), but in the largest fish (MA1) the density was significantly higher $(P<.001)$ in the large retina compared to the small one. The product of cell density and retinal area showed, in all three animals, that the larger retina contained a greater number of labeled ONL cells (51\% on average) than the smaller retina. In all three fish the distributions of total labeled cells were significantly different between small and large retinae $(P<.001$ for MA1; $P<.01$ for MA3; $P<.05$ for MA2).

\section{Effect on cell number}

Figure 7 shows an example of the camera lucida drawings used for ganglion cell counts, and Table 2 summarizes the data. The estimated number of ganglion cells ranged from slightly greater than 150,000 (eye $331 \mathrm{~L}$ ) to over 200,000 (eye $327 \mathrm{~L}$ ). There was no correlation between incresed lens diameter and increased number of ganglion cells, as in common goldfish (Easter et al., '81), but this is probably due to the normal variability in ganglion cell numbers and the relatively narrow range of lens diameters of the eyes studied here $(0.5 \mathrm{~mm})$. For each animal, the planimetric density of ganglion cells was uniformly lower in the larger retina (Table 2). However, the product of cell density and retinal area showed that the large retina contained a greater number of ganglion cells (18\% on average) than the small one. The distributions of the total number of ganglion cells between the small and large retinas were significantly different $(P<.001)$.

\section{DISCUSSION}

The retina of a teleost fish grows throughout life by two processes: the addition of new neurons (Müller, '52; Johns, '77, '82; Meyer, '78), and a balloonlike stretching of the existing retina, that results in an increase in retinal area and a decrease in neuronal density (Ali, '64; Easter et al., '77; Johns and Easter, '77; Kock and Reuter, '78; Kock, '82). This prolonged period of growth accompanied by neurogenesis makes the goldfish retina a useful tissue in which to study neuronal proliferation. Growth does not proceed at a constant rate in different individuals however, so fish of the same age are often markedly different in size (Müller, ' 52 ; Brown, '57; Raymond, '86). The growth of the eye is, in general, yoked to that of the body, although there is a slight tendency for ocular growth to proceed even though systemic growth has slowed. Thus, among a population of fish identical in size but variable in age, the older ones have slightly larger eyes (Müller, '52). The mechanisms that control ocular growth, and in particular, that regulate production of retinal neurons, are not yet understood in fish nor in any other vertebrate species.

In this study we measured two parameters: one an index of neuronal cell proliferation (No. of thymidine-labeled cells in the outer nuclear layer) and the other an index of neu. ronal number (No. of ganglion cells). These two parameters are not directly related, since dividing cells in the ONL produce only new rods, not new ganglion cells (Johns, '82). 
Ganglion cells, in contrast, are born exclusively in the circumferential germinal zone at the retinal margin (Johns, '77; Meyer, '78). 'The circumferential germinal zone in the Black Moor retinas was labeled in our autoradiographic preparations, but labeled cells there were difficult to count accurately because of their close packing. Labeled rod precursors, in contrast, were spread out across the full extent of the retina and were therefore easily counted. We counted total ganglion cells, and not rods, because the former could be quantified accurately in whole-mount preparations, whereas the later are more difficult to quantify since they must be counted on sections and the numbers corrected for split nuclei. We presume that the total number of rods, like the ganglion cells, was greater in the larger retinas. This assumption seems reasonable, since the number of rows of rod nuclei was similar between eyes (Fig. 6B,C), implying similar planimetric densities, which would yield a larger total number of cells in the retinas with larger area.

Obviously, many factors must interact to control retinal cell proliferation. The most basic are nutritional and hormonal effects that are mediated at a systemic level (Goss, '78). Factors intrinsic to the eye are also implicated by the results of the present study. The fact that the eyes of Black Moor goldfish are often unequal in size implies that ocular growth is at least partially autonomous. In this study we selected fish with asymmetric eyes and compared the smaller with the larger. We found that for each fish the largest eye had the largest retina, the most proliferating cells (Table 1), and the most retinal ganglion cells (Table 2). From this we conclude that the rate of retinal neurogenesis is postively correlated with the rate of ocular growth, and that the same mechanism(s) controls both.

What mechanism(s) might underlie the ocular enlargement and neuronal hyperplasia in Black Moors? It is known that mechanical stretch plays a role in normal ocular growth, which accelerates when the intraocular pressure begins to build within the globe (Coulombre, '56; Mann, '69). The eyes of Black Moors have elevated intraocular pressures (Raymond et al., '84), which may lead to greaterthan-normal stretching of the globe and retina. This is consistent with the observation that retinas in Black Moors are thinner (Fig. 5) and have a lower planimetric density of neurons (Fig. 6) than in normal goldfish. The correlation we observed between ocular size and numbers of both proliferating cells (Table 1) and differentiated neurons (Table 2) suggests that the mechanism responsible for ocular enlargement may also affect mitotic rate. There is direct evidence that stretch is mitogenic for cells in culture. Fibroblasts grown on nylon mesh were subjected to controlled amounts of mechanical stress, and the mitotic index was measured; tension applied to the nylon substrate enhanced the mitotic rate (Curtis and Seehar, '78). The mitogenic effect of stretch may be related to changes in cell shape. Folkman and Moscona ('78) found that endothelial cells plated on substrates of variable adhesivity adopted characteristic shapes ranging from rounded to flattened, and the rate of DNA synthesis was linearly related to the inverse of cell height. This suggests that stretch might exert its mitogenic effect by causing cells to become flatter. It is well known that cells in the basal layer of the epidermis respond to mechanical tension by increasing their rate of cell proliferation. Stretching the skin with implants of silicone rubber (Francis and Marks, '77) or with specially constructed springs (Squier, '80) results in a rapid (within 1 day) increase in ${ }^{3} \mathbf{H}$-thymidine labeling index.
Although stretch is mitogenic for cells in culture, we cannot be certain that this was the cause of the increased cell proliferation we observed. It is possible that the hyperplasia associated with ocular enlargement in Black Moor retinas was only indirectly related to retinal stretching. For example, in the absence of cell addition, stretching would inevitably lead to a decreased cell density, and the lowered density of differentiated cells might have induced mitotic activity. Recent studies of retinal cell proliferation in tadpoles and fish following neurotoxic lesions lend some support to this idea. Reh and colleagues (Reh, '86; Reh and Tully, '86) and Negishi and colleagues (Negishi et al., '82, '87) have demonstrated a selective, transient up-regulation in the production of new neurons, arising from the proliferative margin, following destruction of specific populations of differentiated neurons with an excitotoxin (kainate) or with a catecholaminergic analogue (6-hydroxydopamine). These studies suggested that signals from differentiated cells feed back onto proliferating cells to regulate mitotic activity. In the Black Moor, retinal stretching pulls cells apart, and this might dilute the concentration of these putative regulatory signals, thereby leading to increased neuronal proliferation. This mechanism is formally analogous to the concept of regulation of epidermal proliferation by locally produced inhibitory factors, called chalones (Duell et al., '75).

We have suggested that differential stretch leads to ocular enlargement in Black Moors. However, an alternative explanation might be that their eyes grow larger as a consequence of a higher rate of cell proliferation induced by another as-yet-undefined cause. This seems unlikely for the following reasons. If cell crowding were the motive force leading to retinal growth, it is hard to explain why the affected retina would be thinner and have a lower cell density. Furthermore, Coulombre ('56) cannulated the developing eyes of chick embryos just before they would normally undergo a major growth spurt, and they failed to grow. This experiment provided direct evidence that the rise in intraocular pressure, which occurred concomitantly with the growth spurt, is responsible for it. He further observed that retinas of cannulated eyes continued to grow, even though the globe did not. This observation strongly suggests that retinal "push" cannot cause ocular growth. It also indicates that mechanical forces must not be the only factor controlling retinal cell proliferation.

\section{ACKNOWLEDGMENTS}

This research was supported by NIH EY04318 and a Sloan Foundation Research Fellowship to P.A.R., and by NIH EY05625 and EY07060 and NSF BNS8607886 to P.F.H. We thank Ms. Linda Barthel and Ms. Janet Braisted for help with the figures and Dr. Stephen S. Easter, Jr., for many helpful discussions and the use of his laboratory facilities for parts of the study. Mrs. Sharon Moskwiak typed the manuscript.

\section{LITERATURE CITED}

Ali, M.A. (1964) Stretching of the retina during growth of salmon (Salmon salar). Growth 28:83-89.

Allee, W.C., A.J. Kinel, and W.H. Hoskins (1940) The growth of goldfish in homotypically conditioned water; a population study in mass physiology. J. Exp. Zool. 84:417-443.

Bertsch, S., K. Csontos, J. Schweizer, and F. Marks (1976) Effect of mechan ical stimulation on cell proliferation in mouse epidermis and on growth regulation by endogenous factors (Chalones). Cell Tissue Kinet. 9:445457. 
Brown, M.E. (1957) The Physiology of Fishes. Vol. I. Metabolism. New York: Academic Press.

Coulombre, A.J. (1956) The role of intraocular pressure in the development of the chick eye. I. Control of eye size. J. Exp. Biol. 133:211-225.

Curtis, A.S.G., and G.M. Seehar (1978) The control of cell division by tension or diffusion. Nature 274:52-53.

Duell, E.A., B.S. Kelsey, J.J. Voorhees (1975) Epidermal chalone-past to present concept. J. Invest. Dermatol. 65:67-70.

Easter, S.S., Jr., P.R. Johns, and L.R. Baumann (1977) Growth of the adult goldfish eye. I. Optics. Vision Res. 17:469-477.

Easter, S.S., Jr., A.C. Rusoff, and P.E. Kish (1981) The growth and organization of the optic nerve and tract in juvenile and adult goldfish. J. Neurosci. 1:793-811.

Easter, S.S., Jr., and P.F. Hitchcock (1986) The myopic eye of the Black Moor. Vision Res. 26:1831-1833

Folkman, J., and A. Moscona (1978) Role of cell shape in growth control. Nature 273:345-349.

Francis, A.H., and R. Marks (1977) Skin stretching and epidermopoiesis. Br. J. Exp. Pathol. 58:35-39.

Goss, R.G. (1978) The Physiology of Growth. New York: Academic Press.

Hitchcock, P.F., and S. S. Easter (1986) Retinal ganglion cells in goldfish: A qualitative classification into four morphological types, and a quantitative study of the development of one of them. J. Neurosci. 6:1037-1050.

Johns, P.R. (1977) Growth of the adult goldfish eye. III. Source of the new retinal cells. J. Comp. Neurol. 176:343-358.

Johns, P.R. (1982) Formation of photoreceptors in larval and adult goldfish. J. Neurosci. 2:178-198.

Johns, P.R., and S.S. Easter, Jr. (1977) Growth of the adult goldfish eye. II. Increase in retinal cell number. J. Comp. Neurol. 176:331-342.

Kock, J.-H. (1982) Neuronal addition and retinal expansion during growth of the crucian carp eye. J. Comp. Neurol. 209:264-274.

Kock, J.H., and T. Reuter (1978) Retinal ganglion cells in the crucian carp (Carassius carassius). I. Size and number of somata in eyes of different sizes. J. Comp. Neurol. 179:535-548.

Krauth, J. (1983) The interpretation of significance tests for independent and dependent samples. J. Neurosci. Methods 9:269-281.

Mann, I. (1969) The Development of the Human Eye. New York: Grune and Stratton.
Mednick, A.S., and A.D. Springer (1988) Asymmetric distribution of retinal ganglion cells in goldfish. J. Comp. Neurol. 268:49-59

Meyer, R.L. (1978) Evidence from thymidine labeling for continuing growth of retina and tectum in juvenile goldfish. Exp. Neurol. 59:99-111.

Müller, H. (1952) Bau und Wachstum der Netzhaut des Guppy (Lebistes reticulatus). Zool. Jahrb. (Physiol.) 63:275-324.

Negishi, K., T. Teranishi, and S. Kato (1982) New dopaminergic and indoleamine-accumulating cells in the growth zone of goldfish retinas after neurotoxic destruction. Science 216:747-749.

Negishi, K., T. Teranishi, S. Kato, and Y. Nakamura (1987) Paradoxical induction of dopaminergic cells following intravitreal injection of high doses of 6-hydroxydopamine in juvenile carp retina. Dev. Brain Res. 33:67-79.

O'Leary, D.D.M., J.W. Fawcett, and W.M. Cowan (1986) Topographic targeting errors in the retinocollicular projection and their elimination by selective ganglion cell death. J. Neurosci. 6:3692-3705.

Raymond, P.A. (1985) The unique origin of rod photoreceptors in the teleost retina. Trends Neurosci. 8:12-17.

Raymond, P.A. (1986) Movement of retinal terminals in goldfish optic tectum predicted by analysis of neuronal proliferation. J. Neurosci. 6:24792488.

Raymond, P., D. Spilman, R. Hill, and C. Bahn (1984) The telescopic eyes of Black Moor goldfish: Elevated intraocular pressure and altered aqueous outflow pathways. Invest. Opthalmol. Vis. Sci. [Suppl.] 25:282.

Reh, T.A. (1987) Cell-specific regulation of neuronal production in the larval frog retina. J. Neurosci. 7:3317-3324.

Reh, T.A., and T. Tully (1986) Regulation of tyrosine hydroxylase-containing amacrine cell number in larval frog retina. Dev. Biol. 114:463-469.

Rogers, A.W. (1979) Techniques of Autoradiography, Third ed. New York: Elsevier/North-Holland.

Squier, C.A. (1980) The stretching of mouse skin in vivo: Effect on epidermal proliferation and thickness. Invest. Dermatol. 74:68-71.

Stewart, R.R., D. Spergel, and E.R. Macagno (1986) Segmental differentiation in the leech nervous system: The genesis of cell number in the segmental ganglia of Haemopis marmorata. J. Comp. Neurol. 253:253. 259.

Wheeler, T.G. (1978) Goldfish retina: Dorsal versus ventral areas. Vision Res. 18:1329-1336. 